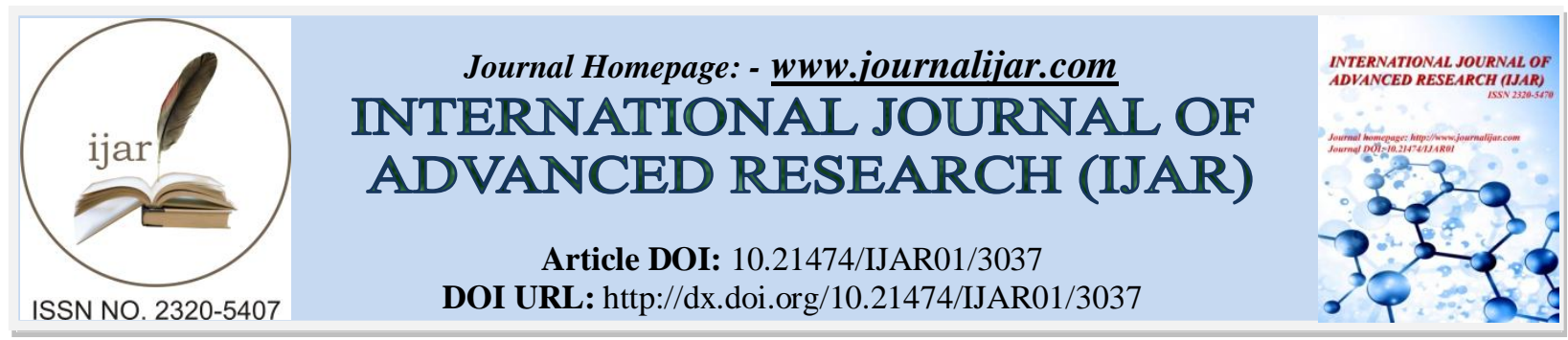

RESEARCH ARTICLE

\title{
FRACTURE DISLOCATION OF PROXIMAL HUMERUS WITH INTRATHORAIC DISPLACEMENT OF THE HUMERAL HEAD. A RARE PRESENTATION.
}

Dr. Nilesh Kachnerkar and Dr. Anil Dhule.

Assistant Professor, Department of Orthopaedics, GMCH Aurangabad(M.S.), India.

\section{Manuscript Info}

Manuscript History

Received: 30 November 2016

Final Accepted: 28 December 2016

Published: January 2017

Key words:-

Fracture dislocation proximal humerus,

Intrathoracic migration, Neers

Prosthesis.

\section{Abstract}

High velocity trauma results in fracture dislocation of the proximal humerus.Dislocated fragments of the proximal humerus fracture very rarely migrate into ipsilateral hemithorax .The dislocation adds an extra level of difficulty to the treatment of complex multipart proximal humeral fractures with higher risk of osteonecrosis. Classified as 11B3 by OTA classification. To our knowledge this is among the very few cases reported till date of intrathoracic humeral head migration.

Copy Right, IJAR, 2016,. All rights reserved.

\section{Introduction:-}

Fracture -dislocation of the humeral head into the thoracic cavity is a rare injury and there is no consensus on its treatment. We report the presentation and management of this injury in a 50-year female in developing country.

\section{Case report:}

A 50 year old female had a road traffic accident with the vehicle falling over the bridge. The patient was brought to the emergency department with pain and swelling of left shoulder and inability to move shoulder joint. The general examination was unremarkable. On local examination patient had tenderness over shoulder and left side of chest without any neurovascular deficit distally in the limb. All movements of shoulder joint were restricted. Radiological examination with $\mathrm{x}$ ray shoulder revealed communited fracture proximal humerus with ipsilateral intrathoracic dislocation of humeral head. NCCT shoulder and chest was done with 3-D images showing posterolateral migration of head into ribcage. Usg chest showed haemothorax. Patient was posted in emergency for thoracotomy for removal of humeral head. Under general anesthesia in right lateral position a lateral incision was taken on 4 th intercostal space, dissected layer by layer to expose the rib. The rib was cut and pleural space was entered . The humeral head without any soft tissue attachment was found posterolaterally in pleural space. An ICD was kept and incision closed in layers. Patient was allowed to stabilise after thoracotomy and later posted after 2 weeks for SHOULDER HEMIARTHROPLASTY. Under general anesthesia and in supine postion a deltopectoral approach was used for exposure of proximal humerus. The greater tuberosity and lesser tuberosity fragments with attached muscles were identified which helped for clinical judgement. The humerus cannal was prepared and cemented Neers prosthesis of size $35 \mathrm{~mm}$ was inserted. The prosthesis was reduced in glenoid cavity having good stability. The rotator cuff was repaired along with the reduction of greater and lesser tuberosity. Wound wash given ,drain kept and incision closed in layers. Physical therapy and rehabilitation programme followed with good range of motion. 


\section{Results and Discussion:-}

Fractures of the proximal humerus are sometimes associated with dislocation of the proximal fracture fragment, occurring more commonly anteriorly than posteriorly [7]. Rarely the dislocated fragment migrates into the ipsilateral hemithorax and may be associated with single or multiple rib fractures[1-6]. Associated pneumothorax or haemothorax occurred in some cases[2-4]. One case was managed nonoperatively with humeral head left within the thoracic cavity without apparent sequale[3]. Regarding the mechanism of ipsilateral intrathoracic dislocation one study suggested that a sudden abduction force was sufficient to both fracture the humerus and drive the dislocated humeral head between the ribs[3]. Another study suggested that a force along the humeral shaft could force the dislocated head into the thoracic cavity[4]. Needs carefull and vigilant $\mathrm{x}$ ray evaluation in emergency followed by CT scan. As the humeral head has no muscular or capsular attachment left so blood supply to head is disrupted, hence head osteonecrosis is inevitable so total shoulder arthorplasty or hemiarthroplasty is the surgery of choice.

\section{Legends:-}

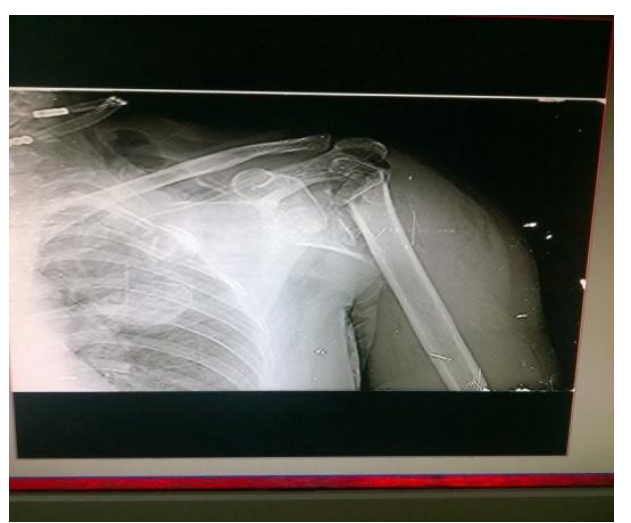

Fig 1:- X-ray shoulder in emergency department

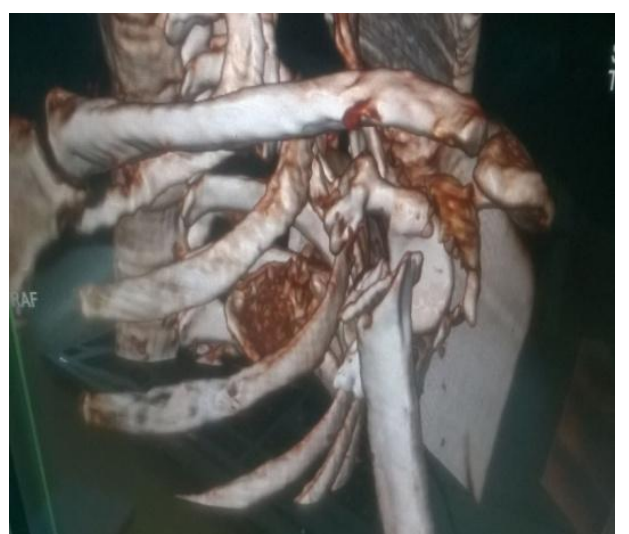

Fig 2:- 3D CT showing intrathoracic humeral head 


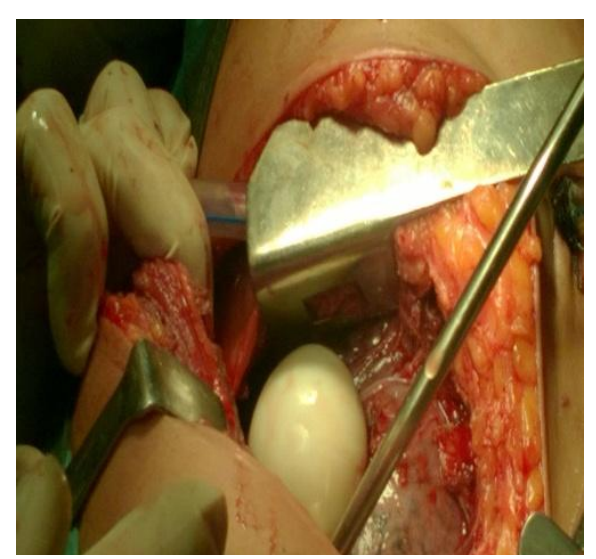

Fig 3:- Humeral head found postero-laterally in pleural space

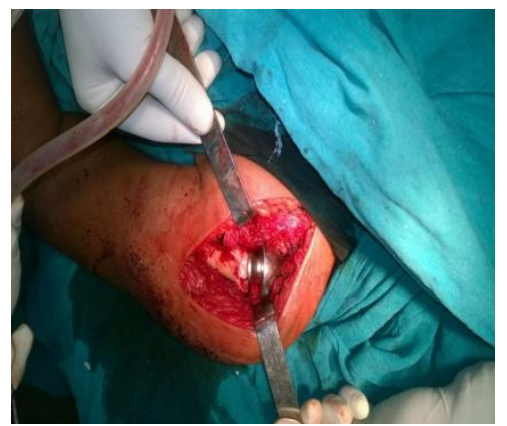

Fig 4:- Cemented Neers prosthesis reduced onto glenoid

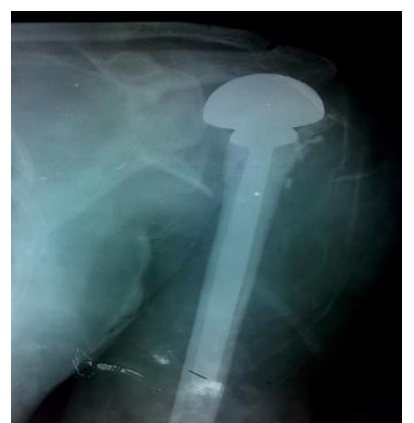

Fig 4:- Postoperative X-ray with Neers prosthesis

\section{References:-}

1. West EF. Intrathrocic dislocation of the humerus. J Bone Joint Surg Br 1949;31-B:61-62

2. Glessner JR. Intrathoracic dislocation of the humeral head. J Bone Joint Surg Am 1961;43-A:428-430

3. Patel MR, Pardee ML, Singerman RC. Intrathoracic dislocation of the head of the humerus. J Bone Joint Surg AM 1963;45-A:1712-1714

4. Hardcastle PH, Fisher TR. Intrathoracic displacement of the humeral head with fracture of the surgical neck. Injury 1981; 12:313-315

5. Kaar TK, Rice JJ, Mullan GB. Fracture dislocation of the shoulder with intrathoracic displacement of the humeral head. Injury 1955;26:638-639

6. Brogdon BG, Crotty JM, MacFeely L, McCann SB, Fitzgerald M. Intrathoracic fracture dislocation of the humerus. Skeletal Radiol 1995;24:383-385

7. Rogers LF. Radoilogy of skeletal trauma, $2^{\text {nd }}$ ed. New York: Churchill-Livingstone, 1992:696-804 